\title{
Social Networking as a Facilitator for Lifelong Learning in Multinational Employee's Career
}

\author{
Andreea Nicoleta VISAN, Florentina Marinela OLTEANU \\ Bucharest University of Economic Studies, Romania \\ visan.nicoleta@ymail.com,olteanu.florentina@hotmail.com
}

\begin{abstract}
This paper discusses how multinational employees who are leaving in Bucharest, Romania use social networks as a tool for their everyday tasks and work, and how they want to satisfy their personal development needs by having access to information from these digital platforms. The case study described was conducted in Bucharest in 2017 and followed a results analysis with structured tables and graphs. In the study took part 24 participants who were selected among multinational IT employees in Bucharest. Social networks contribute to employee's lifelong educational process: besides providing them positive gratification, they also contribute to their personal development and careers growth. Even though all individuals who participated in this study use social networks, more efforts should be done in order for companies in Bucharest to know the benefits of social networks and employee's opinion about their contribution to lifelong learning.
\end{abstract}

Keywords: Social Network, Lifelong Learning, Multinational Companies, Bucharest

1 Introduction

According to OECD (Organization for Economic Co-operation and Development), people are constantly learning everywhere and at all times. Every day in everyone's life brings additional skills, knowledge and/or competences [1]. Nowadays, information is present in every place and is easier to access it as never before.

Lifelong learning (LLL) is a process in which every human being should be involved because this means health, youth and more important, sharper mental abilities that help people to cope and adapt easily to modern times. Adults have to understand they have an obligation to themselves to continue learning throughout their whole life. The world is changing so quickly that if we do not consider LLL and we do not keep growing and developing, we will soon be left behind [2].

On the other hand, change is life and we cannot do much to control this so we have to adapt and deal with the growing speed of the technology. People are increasingly interested in cultivating their virtual social relationships and the social networking websites provide proper platform to express themselves. These websites give the chance to meet new people and establish new virtual relationships and connections with access to multiple source information [3].

The social network is a theoretical construct useful in the social sciences to study relationships between individuals, groups, organizations, or even entire societies. The term is used to describe a social structure determined by such interactions. The ties through which any given social unit connects represent the convergence of the various social contacts of that unit [4]. You can make the lifelong learning experience more engaging and enjoyable for your audience by integrating social networks into the process. Encourage them to have access to like-minded individuals on social networks sites or even create an internal social network that brings together all people with the same interest. The scope is to have the chance to be surrounded by other online lifelong learners and to be able to collaborate and share learning passion [5]. From an educational perspective, online social networking has become also a learning practice for university students since they occupy a large proportion of the total population of social networking websites. We all can observe that social networking takes most of young people's time and it is deeply embedded in their lives. Social networking is more likely to become self-initiated learning, which can lead to lifelong learning, in which 
individuals create a system of information and support it by building and sharing personal links. In this way, people can interact with their peers and get feedback and thus improve their performance [3]. The question regarding social networking in education is: What impact can social networks have on students learning?

This model is prone to be taken as example by multinational IT companies which invest in hiring more and more students since they come with the latest technology knowledge. In most cases, the social network is hosted on the company Intranet and there can be added news about events or conferences but also workshops and technical courses. Moreover, they want their senior employees to share their experience with junior employees in a responsible, clear but friendly way and what can be friendlier than an environment with which students are already used to, social networking?

The purpose of this article is to analyze the relation between LLL and social networks within the employees of several companies in Bucharest, Romania. More specifically, this article is focused on showing the popularity of social networks, how the multinational employees feel about them, the effect they have at company level from the learning point of view and also its connection with alternative or modern way of learning.

\section{Literature review}

It is widely known that we live in a world where technology is influencing our lives. If, in the past, people used to go out and socialize, nowadays they have the possibility to do that through the internet from the comfort of their homes using social networking platforms. Moreover, people have started using these platforms not only for socializing but also for studying, sharing ideas and opinions on different themes.

That being said, we live in a world that is rapidly changing due to the constant growth and improvement of technology. Thus, society needs to keep up with the changes and the best solution for that is to keep learning new things every day. The learning society is the vision of a society where there are recognized opportunities for learning for every person wherever they are and however old they are [6].

While instructors cannot always accommodate each student's need, it is important to provide several learning opportunities to students. As a result, online social networking can be implemented in education [7]. An adult survey conducted by Futurelab in 2009 reports, among other findings, that $94 \%$ of participants actively engage in informal learning. In the same report, surveyors found that $79 \%$ of participants spend about $8 \frac{1}{2}$ hours of leisure time per week learning through technology (via the internet, television, DVDs and videos), mostly at home [8].

Many different studies have been made on lifelong learning throughout online media, namely social networks. In 2008-2010, Hypermedia Laboratory of Tampere University of Technology (TUT) conducted a research in which students were asked what are the main characteristics of social media enhanced learning and what motivates students to use social media services in an educational context [9].

The following issues were highlighted in students' answers. Social media tools are easy to use, suitable tool for promoting different events for students, it was motivating to follow friends' events, content and profile information, content feeds in a user dashboard were considered to be motivating. A function like or dislike content and features was desired, likewise listings of the most popular content, users, actions, etc [9].

Similarly, in 2009, a research study was made at central campus of the University Houston. The research was made with a total number of 221 students and the results that came out showed that three top-used social media tools are Facebook, Wikipedia and YouTube. The main reasons for using those are listed as: social engagement, direct communication, speed feedback, and relationship building [10].

\section{Research method}

The research is based on a detailed survey 
analysis of the use of social networking by multinational employees in Bucharest, studied through data collected via online form. Participants were selected through a sample survey: multinational employees from different companies with over 50 employees were chosen to take part in the study. When the participants were being selected, two distinct sampling methods were followed: easily accessible and maximum diversity sampling. So, first of all, the project included employees from 3 different IT companies in Bucharest.

A basic condition of the research was that all 24 people involved within the sample had access to their own personal computer with Internet access. The number of participants from each company was not limited but they were chosen based on gender, age and work experience. In the end, there were 11 male participants and 13 female participants, with ages between 23 and 40 years old and average of age was at 29.2, one of them having junior experience, 9 having 1 to 3 years of experience and 14 having more than 3 years of work experience.

A structured online feedback form was used to collect the data. When this questionnaire on "Social networks for employees" was prepared, a special attention was paid to ensuring clarity and quality of the questions and communicate effectively, in the same time leaving space for the possibility of detailed answer or personalized answer and avoid putting pressure on the participants or bore them with long and complex questions, or too many questions with detailed answers, so that they quit going further with the survey. The feedback form was made up of 10 questions, beginning with asking how many years of work experience the person has. In the next 2 questions the multinational employees were asked about their habits of using social networks. The next 2 questions asks straight forward for participant's opinion about social networks related to learning process. The last 5 questions concentrates on company's way of integrating social networks in the employee's everyday work.

Regarding the types of questions, in the survey were used 2 simple questions with only one answer, 3 question with Yes/No answer, 2 questions with multiple answers, one open question for the participant to fill in and 2 evaluating questions using grades from 1 to 5 or 1 to 10 . The content of the data gathered from the survey was analyzed and the questions were taken as the basis for the study, specifying and interpreting them. In order to ensure accuracy in the analysis and no mistakes in collecting the data, all data was introduced by every participant online and this site took care of storing the answers and gave the opportunity to export in various formats, so that the conclusions would be clear and understandable.

\section{Results}

We took into the sample people with different work experience so that this factor won't be unbalanced and won't influence too much the results. As you can see below, the majority of the participants (14 out of 24) have more than 3 years of experience in their area and 10 out of 24 have between 0 and 3 years of experience, Figure 1. The limits of the years of work were established taking into account that, for IT companies, the employees are young. This fact is also proved by the age of the participants: between 23 and 40 years.

\begin{tabular}{|lc|c|}
\hline 1. Work experience & & \\
Junior & 1 & $4.2 \%$ \\
\hline $1-3$ years & 9 & $37.5 \%$ \\
\hline more than 3 years & 14 & $58.3 \%$ \\
\hline Total răspunsuri & 24 & \\
\hline
\end{tabular}

Fig. 1. Question 1 - Work experience 
Employees habits were put under question 2 and 3 (see Fig. 2). In this part of the study, we measured the usage of social networking during work schedule and also their favorite activities during the time spent on the network. The results were stunning, 23 out of 24 employees use social networks during work hours and most often they search for learning something new $-43.8 \%$. People want to learn something new all the time, this being part of lifelong learning, so when they search over and over again for new information in social networks, they permanently link the social networks with lifelong learning. This may be caused by lots of factors like age and curiosity, but it definitely has a connection with innovation from IT technology and the fact that people in this area are prone to be the biggest "information consumers" on the market. Because of this, they should be encouraged to find the information they need quickly and easy and give them the confidence that they will have access to it all the time and in a very friendly manner.

Also, the fact that $95.8 \%$ of the participants revealed that they use the social networks at work, shows the accessibility and span of the social networks and that they should be more and more exploited because the potential is high.

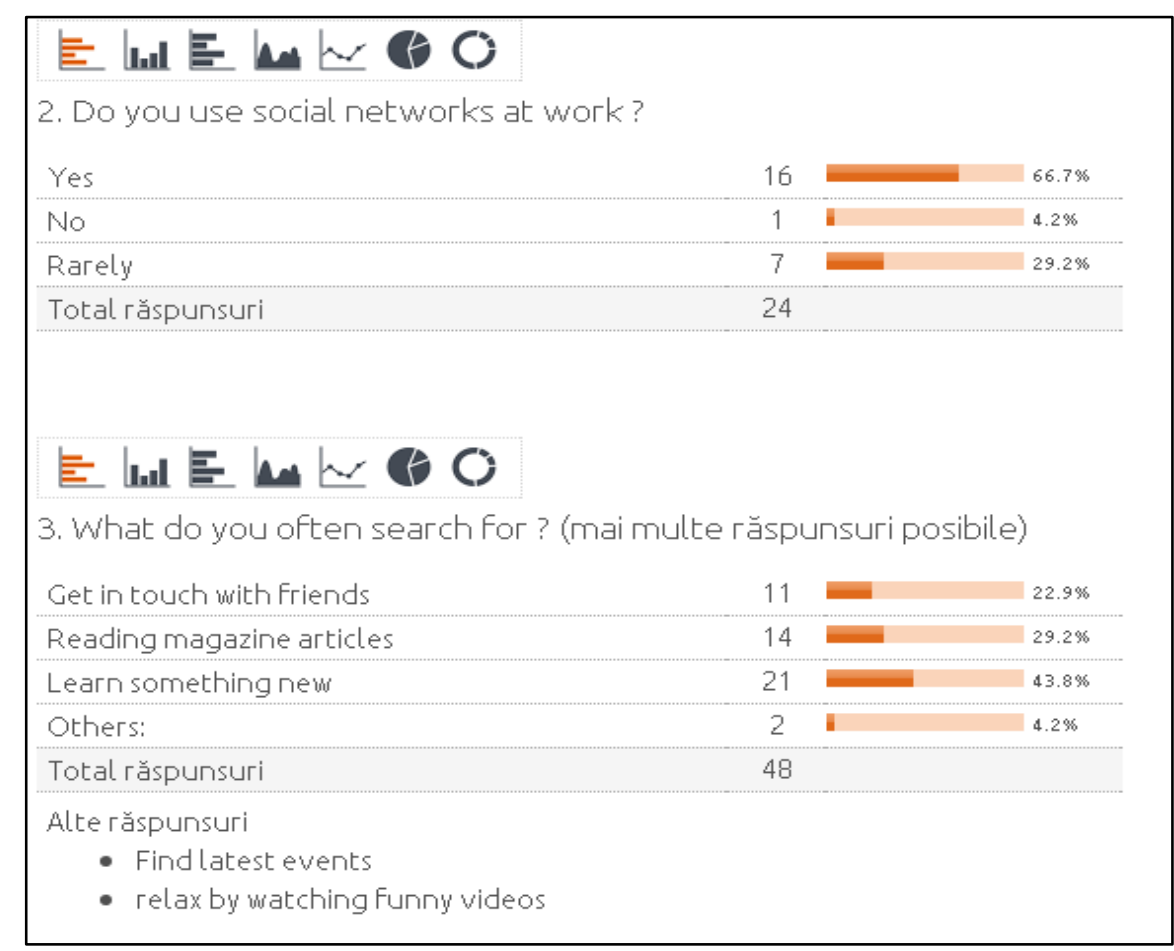

Fig. 2. Questions about employees' habits

The section where the people's beliefs have been questioned shows that $79.2 \%$ of them are sure about the learning potential of the social networks and $20.8 \%$ have some doubts but none of them thinks that social networks cannot be used for learning. Furthermore, $87.5 \%$ of the participants believe that their learning process can be facilitated and made transparent by using social networks (Fig. 3). This is a big step ahead for lifelong learning, considering people are confident that one of the easiest way for continuous learning would be integrating LLL with modern social networks. 


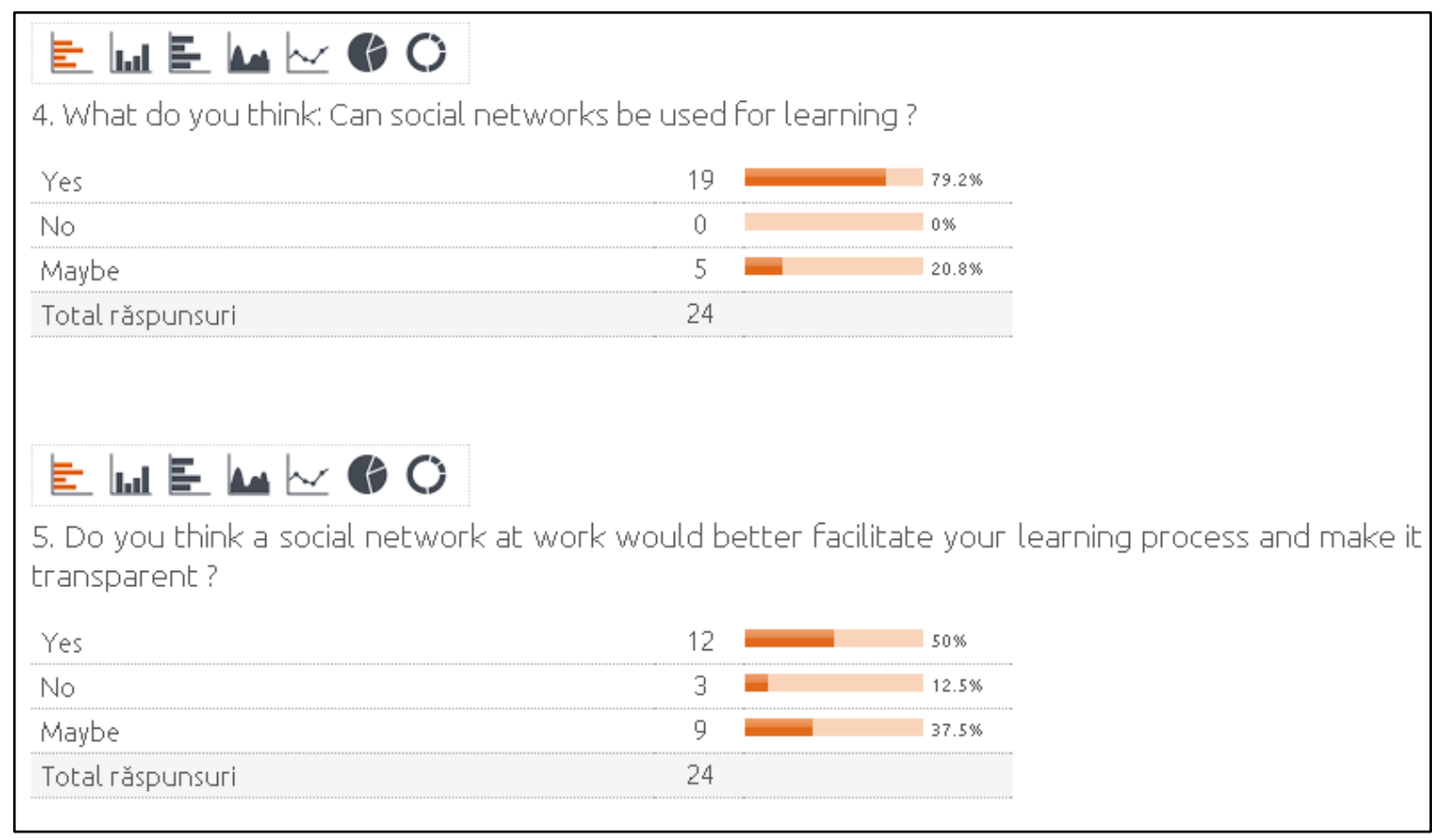

Fig. 3. Participant's beliefs

The last section goes into more details with 5 questions about the integration of social networks in the company and work processes. First of all, the firm's attitude towards social networks is very important, so it was questioned the purpose for which they are used in every company (Fig. 4). The question could have multiple answers and besides the fact that the recruiting and commercial purposes are popular, the majority of votes went to learning and sharing information purpose. The responses indicate that the companies are focusing more and more on making lifelong learning processes accessible.

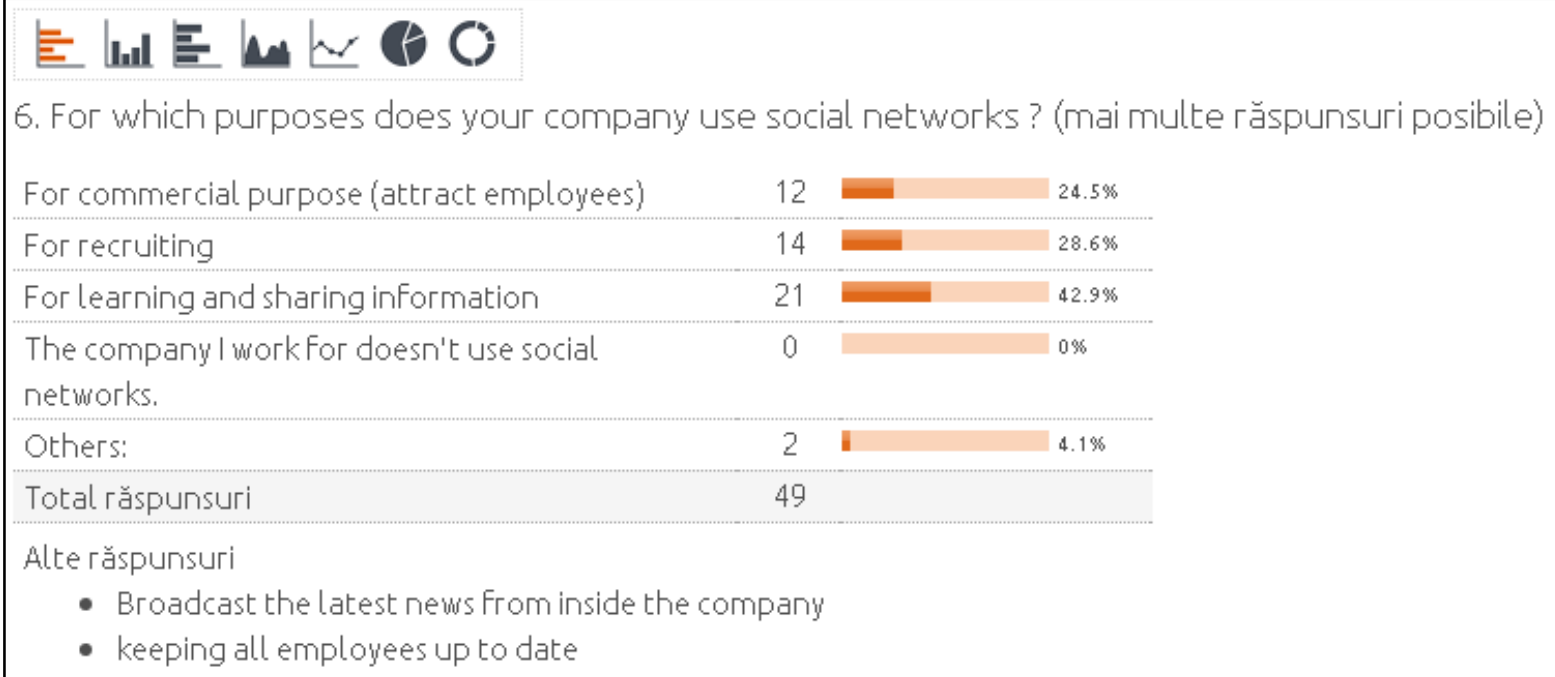

Fig. 4. Social network's purpose in companies

In addition, all 3 companies chosen in this sample have at least one account on a public or internal social network, so $100 \%$ connectivity and transparency (Fig. 5). A very important point to consider is that companies have started building their own internal network on their Intranet on which they can share in a secure manner all confidential documents and information. 


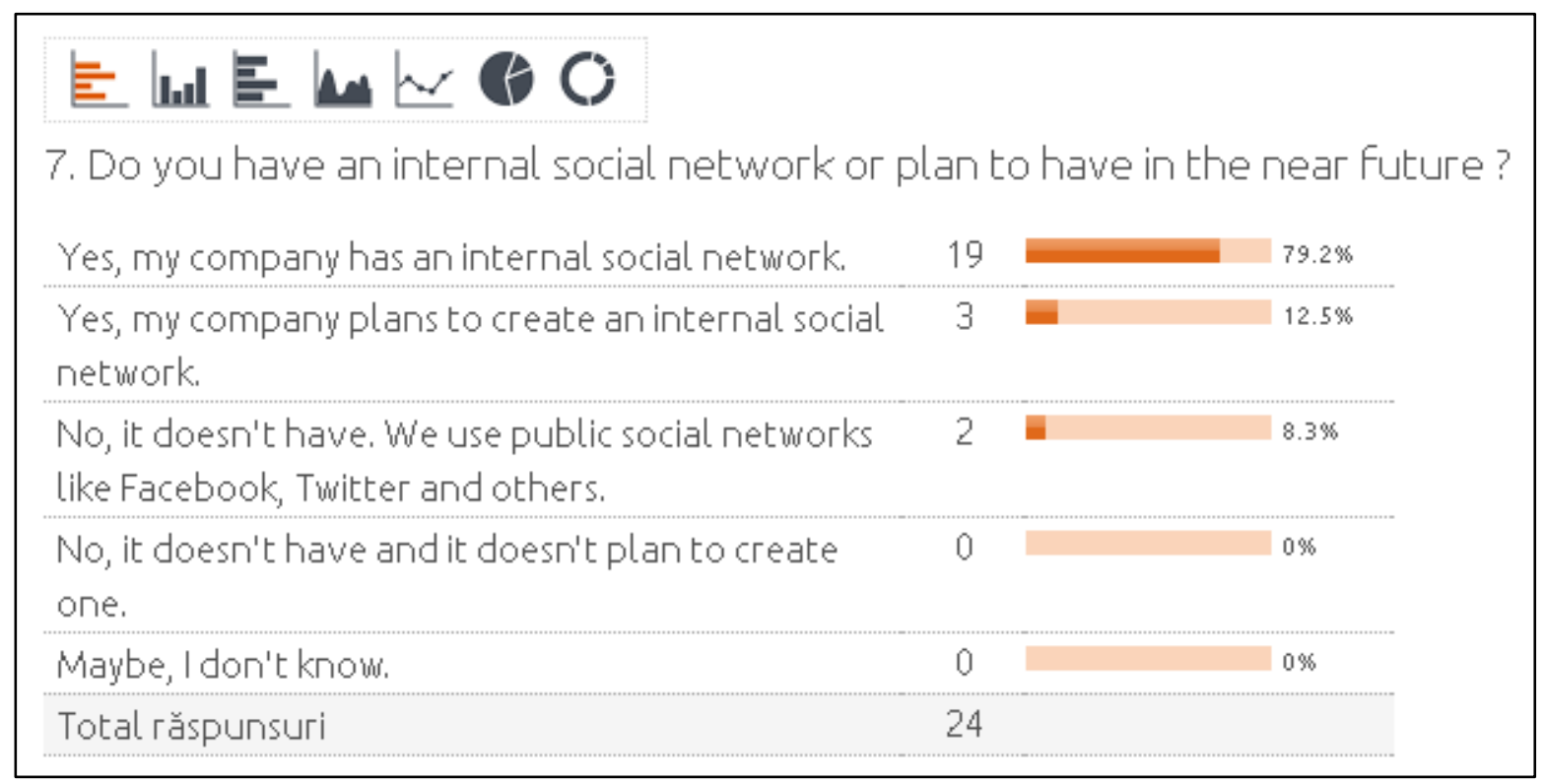

Fig. 5. Company's connectivity

Moreover, participants were asked to note some of the functionalities of their company's social network. While some of them said they use the social network to find out news about trainings, conferences, workshops, strategic actions, decisions and company's vision, the majority said they can find also materials about work processes from every area of the firm, staff information for contact and other useful documentation. Table 1 contains the answers from several participants.

Table 1. Participants' quotes

\begin{tabular}{|l|l|}
\hline Participants & \multicolumn{1}{c|}{ Answer } \\
\hline Participant 2 & $\begin{array}{l}\text { "On our social network site, we can share our thoughts with other employees } \\
\text { better and more quickly, we can communicate more quickly and in a more } \\
\text { dialogue-oriented way - including with your superiors and we can retrieve and } \\
\text { share knowledge in a targeted manner. The site is internal." Participant 4: "On } \\
\text { our internal site we can find news about financial and statistical staff and about } \\
\text { our target market. Also, you can upload and download materials that you think } \\
\text { may be useful for other people. Recently, I have found on our social network, } \\
\text { a presentation about reporting which helped me a lot. By the way, our social } \\
\text { network is called United and I think the purpose it's clearly stated in the name: } \\
\text { learning and sharing information together." }\end{array}$ \\
\hline Participant 5 & $\begin{array}{l}\text { "The company uses Facebook and on our site you can find news about events } \\
\text { and social meetings. Also, there are some statistical information which may be } \\
\text { helpful." }\end{array}$ \\
\hline Participant 15 & $\begin{array}{l}\text { "There are plans for creating an internal social network for storing all learning } \\
\text { materials and help new employees to better accommodate and assimilate the } \\
\text { information." }\end{array}$ \\
\hline Participant 16 & $\begin{array}{l}\text { "On the new internal social network, the company will share processes and } \\
\text { information within all departments. There will be technical and business } \\
\text { information involved." }\end{array}$ \\
\hline Participant 20 & $\begin{array}{l}\text { "We have an internal site where we can find all the information we need in } \\
\text { order to do our job well. We can find information such as: internal procedures, } \\
\text { scripting rules, internal rules, reading material, trainings, quizzes." }\end{array}$ \\
\hline
\end{tabular}




\begin{tabular}{|l|l|}
\hline Participant 21 & $\begin{array}{l}\text { "Our social network site is internal and used for exchanging information. This } \\
\text { new communication tool gives employees the opportunity to connect with } \\
\text { colleagues around the world. The goal is to facilitate our day-to-day work by } \\
\text { encouraging dialogue and the sharing of knowledge. It allows its users to } \\
\text { communicate directly, to find experts on certain topics within the company } \\
\text { more quickly. Here you can learn about IT courses, for example, and also about } \\
\text { the largest relay run in the world, the Düsseldorf Marathon. This platform } \\
\text { allows every employee to play an active part in shaping the future of the } \\
\text { company." }\end{array}$ \\
\hline
\end{tabular}

The last statement, from participant 21 shows the deep culture of his company social network and its strength and involvement in the work of every employee. It also encourages people to share ideas and knowledge, so it's, at the same time, a base for innovation and lifelong learning. An advantage is that all employees have access to the same information so they can better contribute to determine and shape the future of the company.

From the results of the last 2 questions, it appears that the participants appreciate the help of the company's social network in finding useful information for their everyday work with a grade of $3 / 5$. What's more, participants have granted $6.46 / 10$ grade for their company's social network considering it as a learning material (Fig. 6). It is clear that there is room for improvements, but social networks have made their way in people's working environments and they are going to stay there for a while as long as everyone sees them as a helpful tool rather than a threat.

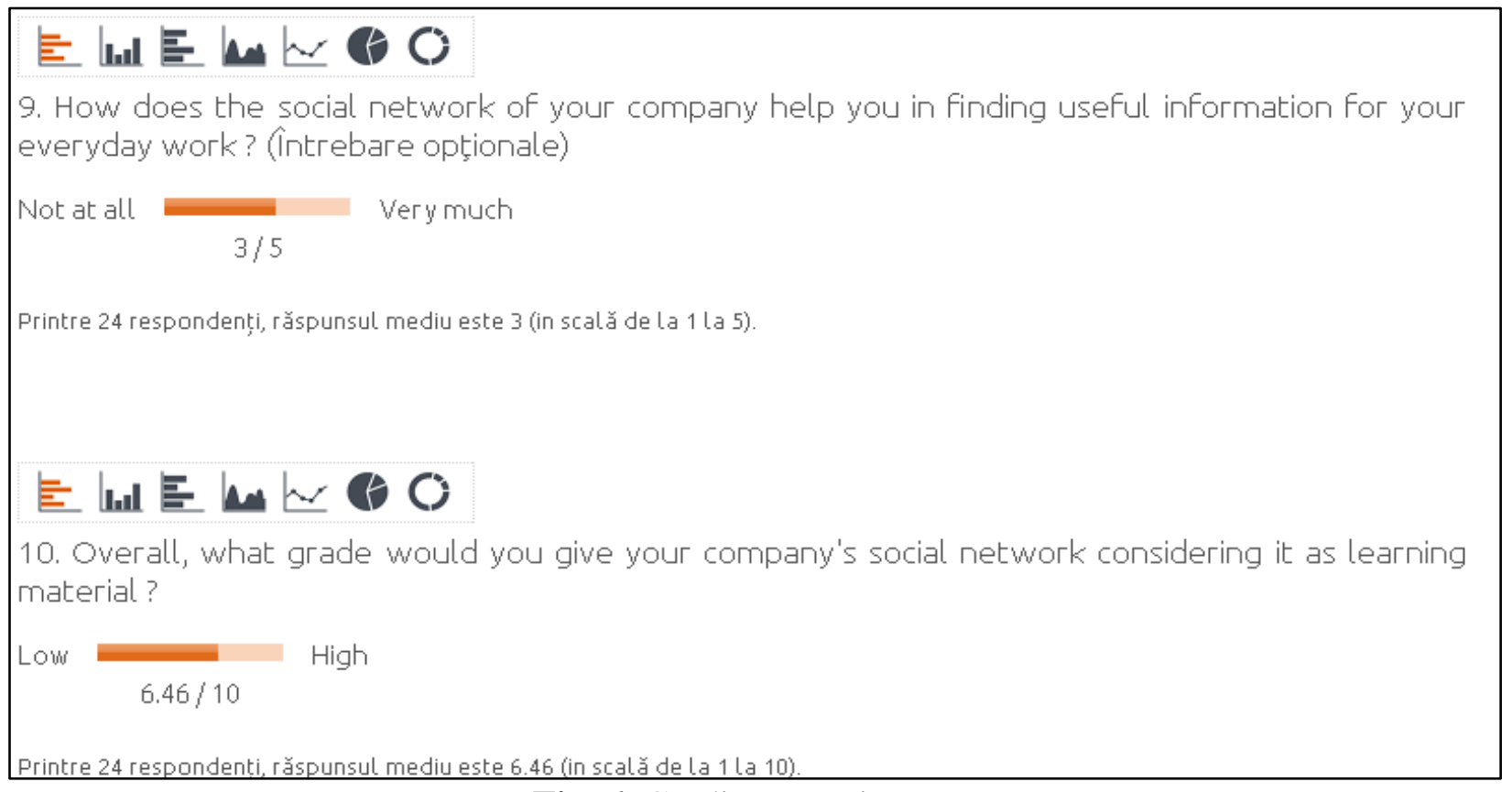

Fig. 6. Grading questions

\section{Conclusions}

In this study, we researched the behaviors of multinational IT companies, focusing on their use of social networks as part of their lifelong educational and development goals. According to their own accounts, their habits with respect to social networks are determined by their aims. In general, employees who use social networks do so in order to get in touch with people, read magazine articles, relax by watching funny videos or find latest events, but most of them want to learn something new every time they access it. These people have the lifelong learning feeling and regardless of 
the thoughts that social networks learning is "non-formal", it's still a concrete and continuous educational process. In such nonformal learning environment, user-generated content can be share with ease. This kind of sharing and the interactivity with replies and comments have a positive effect on employee's socializing skills, education, general culture and also learning process.

Social networks contribute in lifelong education to the personal development of multinational employees, confirming that additional contact with social sites, preferably internal, adds value to their knowledge and improvement of their careers. There is no doubt that awareness should be increased of the importance of social networks in raising knowledge levels and providing personal development as part of lifelong learning [11].

\section{References}

[1] OECD (2017). Recognition of Non-formal and Informal Learning - Home. Retrieved from: http://www.oecd.org/edu/skillsbeyond-school/recognitionofnon formalandinformallearning-home.htm

[2] L. Marjan, L. Ashkan, Challenges for lifelong learning. Procedia - Social and Behavioral Sciences, 47, 2012, pp.1-2, doi: 10.1016/j.sbspro.2012.06.857.

[3] Y. Angela, W. Stella, V. Douglas, K. Ron Chi-Wai, Can learning be virtually boosted? An investigation of online social networking impacts. Computers \& Education, 55, 2010, pp.1-2, doi: 10.1016/j.compedu.2010.06.015.

[4] Wikipedia (2017), Social network. Retrieved from: https://en.wikipedia.org/wiki/Social_netw ork

[5] C. Pappas, 7 Tips To Turn Your eLearning Audience Into Lifelong Online Learners eLearning Industry, eLearning Industry. 2016. Retrieved from: https://elearningindustry.com/7-tips-toturn-your-elearning-audience-into-

lifelong-learners.

[6] A. Green, The many faces of lifelong learning: recent education policy trends in Europe. Journal of Education Policy, 17 (6), 2002, 611-626, doi: $10.1080 / 0268093022000032274$.

[7] C. H. Tu, M. S. NcIsaac (2002), The Relationship of Social Presence and Interaction in Online Classes. The American Journal of Distance Education, vol. 16, no. 3, pp. 131-150. Retrieved from:

https://www.mentormob.com/hosted/card s/71178_cfc5725a0c013f51c6279e4e3fda ed03.pdf

[8] C. Hague, A. Logan, A review of the current landscape of adult informal learning using digital technologies. Bristol: Futurelab. 2009. Retrieved from: http://preview.futurelab.org.uk/resources/ documents/project_reports/becta/Adult_I nformal_Learning_educators_report.pdf

[9] K. Silius, M. Kailanto, A.M. Tervakari, Evaluating the Quality of Social Media in an Educational Context. iJET, Volume 6, Issue 3, September 2011, (pp21-26). Retrieved from: http://onlinejournals.org/i-jet/article/view/1732

[10] Y. Liu, Social media tools as a learning resource. Journal of Educational Technology Development and Exchange, 3(1), 2010, (pp101-114). Retrieved from: http://livernspleen.com/wpcontent/uploads/2013/09/social-mediatool-as-a-learning-resource.pdf

[11] M. Ersoy,A. Güneyli, Social Networking as a Tool for Lifelong Learning with Orthopedically Impaired Learners. Educational Technology \& Society, 19 (1), 2016, 41-52. Retrieved from: http://www.ifets.info/journals/19_1/5.pdf 


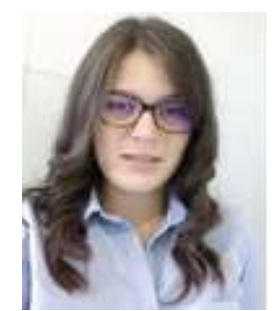

Andreea Nicoleta Vișan has graduated the Faculty of Economic Cybernetics, Statistics and Informatics in 2015. Currently, she is aiming for the Master's degree in Economic Informatics and she works in a multinational company in Bucharest. She joined the company since January 2015, as a trainee in the first 6 months and as a professional quality assurance specialist afterwards. Her work focuses on data warehousing and business intelligence area.

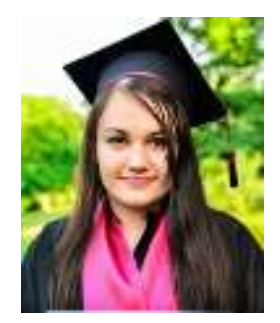

Florentina-Marinela Olteanu has graduated the Faculty of Economic Cybernetics, Statistics and Informatics in 2015. She is currently pursuing the Master's degree course in Economic Informatics and she is also working as a specialist officer of the Romanian gendarmerie. She holds a Cambridge ESOL Level 2 Certificate in Advanced English and an ECDL Core Certificate. 